\title{
A study on effects of smoking on society: a case study
}

\begin{abstract}
Smoking is a very hazardous problem in the whole world. The smoking of a cigarette/ cigar is not only harmful to the lungs of that person who is smoking but also harmful to the people surrounding him. Sometimes the smoking becomes responsible for the road accident when it use by the person who is driving four wheeler or two-wheeler and it is also responsible for firing in the forest. Smoking is an addiction and due to that other family members are also being addicted. The aim of this study is to aware the people of the smoking. The study is focused on the risk assessment of interruption of smoking habits.
\end{abstract}

Keywords: smoking, cigarette/cigar, harmful effects, human health smoking, cigarette/cigar, harmful effects, human health
Volume 7 Issue 4 - 2018

\author{
Shipra Gupta,' Vijay Kumar² \\ 'Department of Management, SGRR University, India \\ 2Department of Physics, Graphic Era Hill University, India
}

Correspondence: Vijay Kumar, Associate Professor Department of Physics, Graphic Era Hill University, Dehardun-24800I, Uttrakhand, India, Email drvijaykumar.geu@gmail.com, vijay_phd05@rediffmail.com

Received: May 15, 2018 | Published: July 25, 2018

\section{Introduction}

\section{The physical process of smoking}

Today, the smoking of a cigarette/cigar becomes a prevalent fashion worldwide. ${ }^{1}$ When any person drives the car, the act of taking a cigar/cigarette out of the pocket, finding match box/lighter and coordinating your hands to light the cigarette means you are likely to divert your attention away from the road. Once you have lit it, you then require putting lighter and packet of cigarettes anywhere. Any distractions like these reduce your skill to react to situations on the road quickly. It is observed that when smokers are lighting up in a car the driving distraction time is around 12 seconds, which is $160 \mathrm{~m}$ at $50 \mathrm{kph} .{ }^{2}$ While you are smoking, you can choose to keep the windows up with the air habituation on, or you can open the window to let the some out. If you open the window, you repeatedly turn towards it to blow the smoke, but sometimes it becomes dangerous for the safety of the family members inside the car. If a person lit the cigarette, he/ she expands the smoke around him/her. Due to this, other persons who are walking on the road are affected by the smoke. You will require tapping ash off the cigarette. Many old cars don't come with ash-tray. The ashtray isn't in the line of sight, so you might require taking your eyes off the road to use it; and it may be the reason of accident on the road. If ash of your cigarette/cigar drops onto your clothes, it may be damaged the cloths, or it may be dangerous for our skin or our family members. Another problem is that when cigarette falls on the floor of the car, it can create a real risk of a fire. The center of a cigarette can be as hot as 600 degree Celsius. ${ }^{3}$ If any person passes through the forest and he drops the piece of cigarette on the land of forest, it may be the responsible firing in the forest. Every year more than hundred acres forest of Uttrakhand are destroyed due to the fire. ${ }^{4}$

\section{Review of literature}

\section{The physiological effects while driving}

If you are a smoker and you get the urge to have a cigarette the physiological changes in your body can make you nervous and short-tempered which can lead to you making skin complaint decisions. When a cigarette is lit for smoking, the nicotine hits our brain and has an almost immediate effect of increasing strain. It's a common misconception that smoking reduces nervous tension. The entertainment effect you get is a return to the normal undisturbed state that non-smokers are in all the time. ${ }^{5}$ The smoke also has the direct effect of irritating your lungs and causing a bronchospasm where the airways tighten. Less oxygen is available to be absorbed by the body due to increasing the percentage of smoke. Phlegm production is increased and the probability of coughing is increased. ${ }^{6}$ According to one case study done by the authors on fifty persons, it is observed that driving of car during smoking is more dangerous than driving during talking on mobile phone. In addition to the conditions that produce a considerable driving interruption of smokers, we underline an established shortage of oxygen; the presence of carbon monoxide creates a problem of breathing inside the vehicle. We should also consider another aspect related to smoking addiction while driving vehicles: the environmental harm. In fact throwing cigarette outside the vehicle, when the vehicle is moving, is the common cause of the fire to the edge of the road. The purpose of this study is to make changes in the rules and regulation on road safety to fine smokers behavior during vehicle driving. It is necessary to aware the public about this severe problem.

\section{Indirect effects on family members}

If you are driving a car and your family members are with you, they will be subject to your second hand smoke. Even if you have the window open, quite a lot of smoke is blown by the window back into the car. A study by smoking while driving will be banned in the $\mathrm{U} \mathrm{K}$ as of October 2015 in a move to help cut children's contact to second hand cigarette smoke. ${ }^{7}$ The prohibition is only extended to cars with passengers aged 0-17 years old and there are proposed fines if it goes to court. In the U K 3lakh children are admitted to doctors' surgeries each year through exposure to passive smoke. ${ }^{1,8}$ Other than $U$ K, smoking has been against the law in cars in New South Wales with children aged fewer than 16, with some financial fine; Queensland has a similar law with a fine. ${ }^{9}$

\section{Harmful health effects due to smoking}

If you've been smoking a while then there's a whole list of illnesses which will make life more difficult for you. Smoking increases the risk of heart disease and stroke, atherosclerosis, increases the risk of 
blood clots that can cause heart attack, constriction of blood vessels, increased heart rate and increases blood pressure. ${ }^{10}$ According to one study, about four lakhs deaths are due to the diseases like asthma, cancer, ulcers, live diseases, murder, fires and burns, diabetes and accident while about 5lakh deaths are due to only smoking. ${ }^{11}$

\section{Risks other than health}

As per one study of Italian young people smoker increased the risk of being in an accident by 3.2 times. ${ }^{3,8}$ As per one study in America cigarette smokers was 1.5 times more likely to be in a car accident on the road. A study of 2006 by the National Highway Traffic Safety Administration titled The Impact of Driver in attention on Crash Risk found that the method of smoking in a car increased the accident risk by 2 -3times. ${ }^{12}$

\section{Driving disturbance caused by smoking}

There are the following disturbances due to smoking.

i. Visual disturbance: When drivers search their cigarettes and lighter in the car, the visual distraction occurs results accident.

ii. Cognitive disturbance: The driver's brain is focused on searching and then lighting their cigarette/cigar.

iii. Manual disturbance: Drivers are generally required to remove both hands from the steering wheel to light their cigarette/cigar. Once the cigarette is lit, the driver will keep driving by only one hand to smoke while driving. They will subsequently become unfocused by the need to expel ash either into the car's cigarette tray or out of the window. The whole process of lighting and smoking a cigarette while driving is really dangerous.

iv. According to police data analyzed by Erie Insurance in the Fatality Analysis Reporting System (FARS), a nationwide census of fatal motor vehicle traffic crashes maintained by the National Highway Traffic Safety Administration, in the past two years, over 65,000 people were killed due to a car accident. Of those accidents, 1 in 10 crashes involved at least one distracted driver. ${ }^{13}$

v. In training manual for Commercial Drivers License drivers, the Federal Motor Carrier Safety Administration (FMCSA) strongly discourages smoking during driving. The FMCSA conducted its own five year study into the dangers of smoking while driving a truck and found that smoking was a source of disturbance in $0.9 \%$ of the disturbance-related accident. This equates to approximately 12,780 accidents over the five year period examined. ${ }^{9}$

\section{Material and methods}

For this study, twenty families have been selected in such a way that smoking addicts at least a member of this family. After discussions by these family members, the problems which are facing are raised in this given study. Suggestions are also taken by these families, which are also given in this study. Another twenty families are selected in such a way that the smoking addicts a member and when the family goes to out of the station, he/she is smoking during the driving. The discussions have been done by the family members and the problems which are facing described in this manuscript. The suggestions are also taken and given in this study.

\section{Findings}

We collect all published information related to smoking and summarized it. It is found that smoking is the leading cause of residential or total fire death in all countries of the world with available statistics. ${ }^{14,15}$ Cigarettes/cigar causes numerous fire disasters. ${ }^{16}$ Cigarette lights cause an estimated 1lakh US dollar in our country and one million US dollar in global level fires per year. Smoking causes an estimated $30 \%$ of U. S. and $10 \%$ of global fire death burdens. Smoking's estimated U.S. and global fire costs were 6.95 and 27.2billion dollars. ${ }^{17}$ The table represents that a maximum number of deaths (7.8million per year) are due to hypertension and having the first rank but smoking (5.4million deaths per year) is responsible for second higher rank in the world. ${ }^{2,18}$

\section{Conclusion}

Any study is having some positive and some negative aspects. But after analysis, it is concluded that smoking is having only negative aspects. There is no benefit from smoking. It may be responsible for our bad health and for very dangerous diseases and also responsible for a large number of deaths in India and worldwide (Table 1). Due to the above mentioned problems, our family members suffer very much financial and mental pressure.

Table I This table represents the number of deaths per year due to different diseases $^{19,20}$

\begin{tabular}{lll}
\hline S. No. & Problems & $\begin{array}{l}\text { Number of deaths } \\
\text { resulting (millions } \\
\text { per year) }\end{array}$ \\
\hline 1 & Hypertension & 7.8 \\
2 & Smoking & 5.4 \\
3 & Malnutrition & 3.8 \\
4 & Sexually transmitted diseases & 3 \\
5 & Poor diet & 2.8 \\
6 & Overweight and obesity & 2.5 \\
7 & Physical inactivity & 2 \\
8 & Alcohol & 1.9 \\
9 & Indoor air pollution from solid & 1.8 \\
\hline 10 & fuels & 1.6 \\
\hline
\end{tabular}

\section{Suggestions}

People very well know that smoking is harmful to our health and it is also written on the packet of cigarette but although they smoke. We should start a companying that due to your smoking, your family paying a large number of financial and mental troubles. If a member of the family starts to smoke, the possibility will be increased that other members will start the smoking. Thus we have to produce an environment in our family that nobody will start smoking. Another suggestion is that for the awareness about the harmfulness of smoking, all boards of school, all Colleges and all Universities should be kept this in the curriculum design of the syllabus. So that students have to study and learn about it. It is observed that many families have suffered the problems due to smoking. There is a need to run a campaigning about the harmful effects of smoking and aware the people about it. So that's why, the authors summarize the literature about it and try to highlights the dangerousness of smoking. But it is miserable that after knowing cigarettes/cigar is increasing continuously. Without fail all the harmful effects, the consumption of so we have to aware the people continuously. 


\section{Acknowledgements}

None.

\section{Conflict of interest}

The author declares no conflict of interest.

\section{References}

1. Aubrey DNJ, De Grey. Life span extension research and public debate: societal considerations. Studies in Ethics Law and Technology. 2007;1(1):7-11.

2. Jane E. Anderson, Douglas E, et al. MPH Correspondence information about the author MD, MPH Michael C. Fiore. Treating Tobacco Use and Dependence. 2002;121(3):932-941.

3. Chen J, Li X, Zhang J, et al. The Beijing Twin Study (BeTwiSt): a longitudinal study of child and adolescent development. Twin Res Hum Genet. 2013;16:91-97.

4. Shimkhada R, Peabody JW. Tobacco control in India. Bulletin of the World Health Organization. 2003;8(1):48-52.

5. Mokdad AH, Marks JS, Stroup DF, et al. Actual causes of death in the United States. JAMA. 2005;291(10):1238-1245.

6. Freeman MK, Fleming TD, Fleming TD, et al. Smoking prevalence and cigarette consumption in 187 countries, 1980-2012. JAMA. 2014;311(2):183-192.

7. Nathan John Grills, Rajesh Singh, Rajkumari Singh, et al. Tobacco usage in uttarakhand: a dangerous combination of high prevalence, widespread ignorance, and resistance to quitting. Bio Med Research International. 2015;132120:10

8. Breslau N, Peterson EL. Smoking cessation in young adults: age at initiation of cigarette smoking and other suspected influences. Am J Public Health. 1996;86(2):214-220.
9. Carvajal SC, Granillo TM. Diagnostic and Statistical Manual of Mental Disorders. 4th ed. Washington: DC American Psychiatric Association; 2000 .

10. Controversies in obesity mortality: a tale of two studies. 2014;2:21.

11. Carvajal SC, Granillo TM. A prospective test of distal and proximal determinants of smoking, initiation in early adolescents. Addict Behav. 2006;31(4):649-660.

12. Centers for disease control and prevention. Colorectal Cancer Statistics. USA: CDC; 2015.

13. Carol A, Burke, Laura K. et al. Colorectal Neoplasia. Cleveland Clinic. $2015 ; 12$.

14. Leistikow BN, Martin DC, Milano CE. Fire injuries, disasters, and costs from cigarettes and cigarette lights: a global overview. Prev Med. 2000;31:91-99.

15. Meg Fluharty, M Res Amy E, Taylor, et al. The association of cigarette smoking with depression and anxiety: a systematic review. Nicotine \& Tobacco Research. 2017;19(1):3-13.

16. Arialdi M Miniño, Elizabeth Arias, Kenneth D, et al. Deaths: final data for 2000. National Vital Statistics Report. 2002;50(15):119.

17. Flegal KM, Graubard BI, Williamson DF, et al. Excess deaths associated with underweight, overweight, and Obesity. JAMA. 2005;293(15):18611867.

18. Harvard TH. Smoking, high blood pressure and being overweight top three preventable causes of death in the U.S. 2009.

19. Loughlin J, Karp I, Koulis T, et al. Determinants of first puff and daily cigarette smoking in adolescents. Am J Epidemiol. 2009;170(5):585-597.

20. Senol Y, Donmez L, Turkay M, et al. The incidence of smoking and risk factors for smoking initiation in medical faculty students: cohort study. BMC Public Health. 2006;6:128. 